\title{
Efecto de la concentración de sacarosa en la producción de antocianinas a partir de cultivos celulares de Vitis vinifera L. var. red globe
}

\author{
Effect of sucrose concentration on producction of anthocyanins from cell \\ cultures of Vitis vinifera L. var. red globe
}

\author{
Antonieta Miñano ${ }^{1}$, Julio Chico ${ }^{1}$, Eloy López ${ }^{1}$, Manuel Sisniegas ${ }^{2}$ y Miguel \\ Bobadilla $^{3}$
}

Presentado: 29/11/2003

Aceptado: $\quad 22 / 11 / 2004$

\section{Resumen}

El cultivo de Vitis vinifera «vid» constituye una de las actividades agrícolas de mayor importancia en nuestra alimentación y en la medicina por presentar unos compuestos bioactivos llamados antocianinas conocidas por tener propiedades antioxidantes, anticancerígenas y cardiotónicas. Con la finalidad de aportar con una alternativa diferente a su extracción tradicional se estableció un sistema de cultivos celulares en suspensión con el propósito de determinar la concentración óptima de sacarosa para obtener mayor producción de antocianinas a partir de cultivos celulares de Vitis vinifera «vid» var. red globe. Se adicionaron diferentes concentraciones de sacarosa $(0 \mathrm{mM}, 58 \mathrm{mM}, 132 \mathrm{mM}$ y $175 \mathrm{mM}$ ) al medio de cultivo basal (MB) suplementado con concentraciones separadas de ácido naftalenacético y kinetina como medio inductor (MI). El contenido de antocianinas aumentó a medida que se incrementó la concentración de sacarosa $(132 \mathrm{mM})$ en el medio de cultivo, encontrándose diferencias significativas entre los tratamientos.

Palabras clave: Vitis vinifera, antocianinas, sacarosa, cultivos celulares.

\section{Abstract}

Vitis vinifera "grape» is one edible fruit vine of importance in agriculture activities, besides to have medical properties related to bioactive natural products knowing as anthocyanins, that, they exhibit antioxidative, anticancerigen and cardiotonic activities. In this paper, a system of suspension cell cultures from Vitis vinifera «vid» var. red globe was established to determine the effect of the concentration of sucrose on anthocyanins yield. Different concentrations of sucrose $(0 \mathrm{mM}, 58 \mathrm{mM}, 132 \mathrm{mM}$ and 175 $\mathrm{mM}$ ) into Basal culture Media (BM) supplemented with separated concentrations of naftalnacetic acid and kinetine as Inductor Media (IM), were applied. Anthocyanins yield were increased in according to increment of sucrose concentration $(132 \mathrm{mM})$ in the cell culture. Significant differences among the treatments were founded.

Keywords: Vitis vinifera, anthocyanins, sucrose, cell cultures.

\section{Introducción}

Vitis vinifera, es intensamente cultivado y reconocido en la alimentación humana por su alto valor energético en azucares, sales mine-

\footnotetext{
(1) Laboratorio de Fisiología y Cultivo de Tejidos Vegetales. Facultad de Ciencias Biológicas. Universidad Nacional de Trujillo. Perú.

(2) Departamento de Estadística. Facultad de Ciencias Físicas y Matemáticas. Universidad Nacional de Trujillo. Perú

(3) Sección de Biología. Facultad de Ciencias. Universidad Nacional de Ancash Santiago Antunez de Mayolo. Perú.
}

Email: Antonieta Miñano aminanoz@terra.com.pe rales y vitaminas. Desde un punto de vista médico-farmacológico, su utilidad se ha incrementado notablemente, ya que se ha demostrado que poseen marcadas propiedades cardiotónicas gracias a unos compuestos glucosídicos llamados antocianinas, que están presentes en hojas, frutos y el aceite de la semilla (Decendit y Mérillon, 1996), y cuya función biológica radica en proporcionar permeabilidad y resistencia a los capilares sanguineos (Bruneton, 1991). Asimismo, las antocianinas constituyen colorantes atóxicos que se utilizan actualmente en la industria alimentaria y de medicamentos (Lock, 1997). 
El potencial de los cultivos de células vegetales para la producción de antocianinas es todavía limitado, debido fundamentalmente a factores que determinan una baja productividad de compuestos de interés. Sin embargo, este problema se ha visto parcialmente superado por la selección de líneas celulares altamente productivas, optimización de condiciones físicas y químicas del medio de cultivo, adición a dichos medios de precursores biosintéticos y elicitores, la sobreexpresión de genes codificantes de enzimas claves en las rutas biosintéticas implicadas y a un aumento en la excreción de compuestos deseados al medio (Piñol, 1999; Endress, 1994). Por ello, no es de extrañar el gran interés por la producción biotecnológica a gran escala de estos metabolitos secundarios (Serrano y Piñol, 1991; Evans, 1998).

Además de los reportes sobre la producción de antocianinas en cultivos de células de Fragaria vesca «fresa» (Mori y Sakurai, 1994), Ipomoea batata «camote», (Xu et al., 2001; Xu et al., 2000); Ajuga reptans, (Callebaut et al., 1990), en $V$. vinifera, se han tratado de enfocar algunas investigaciones dedicadas no sólo a estimular su producción (Decendit y Mérillon, 1996); sino también a su acumulación a través del empleo de diferentes niveles de temperatura (Zhang et al., 1998), luz (Sato et al., 1998); concentraciones de amonio (Do y Cormier, 1991), sacarosa y nitrógeno (Kim y Kim, 2002 a y b), y también empleando biorreactores con cultivos celulares para la producción de catequinas, taninos condensados y antocianinas (Decendit et al., 1996). Otra propuesta es la de preparar suspensiones celulares en dos medios, uno de mantenimiento $\mathrm{y}$ otro promotor de antocianinas, en el que se incrementen notablemente su producción (Bailly et al., 1996). Al respecto, Nozue et al. por referencia de Cormier et al. (1989), señalan reportes en cultivos celulares indicando que un aumento en la concentración de sacarosa de 2 a $6 \%$ e incluso hasta de $12 \%$ al medio de cultivo (Pierik, 1990; Lindsey y Jones, 1992; Hurtado y Merino, 1994), estimulan la producción de antocianinas al desarrollar una osmolaridad en el medio inducida precisamente por las altas concentraciones de azúcar (Cormier por referencia de Kim y Kim, 2002a).

Las antocianinas conservan estructuras químicas muy complejas que originan que su síntesis química sea económicamente inviable (Serrano y Piñol, 1991; Lindsey y Jones, 1992; Evans, 1998; Piñol, 1999), razón mas que suficiente para proponer como alternativa el cultivo de células y órganos vegetales con la finalidad de aumentar la cantidad de antocianinas (Evans, 1998). En el presente trabajo nos proponemos determinar la concentración de sacarosa que permita obtener la mayor producción de antocianinas en cultivos celulares de $V$. vinifera L. var. red globe .

\section{Material y métodos}

\section{Material Biológico}

Se utilizaron explantes (hojas) de plántulas in vitro de $V$. vinifera var. red globe obtenidas en el laboratorio de Fisiología y Cultivo de Tejidos Vegetales de la Universidad Nacional de Trujillo.

\section{Obtención de Callos}

En una cámara de siembra en condiciones de asepsia y esterilización, se procedió a introducir en viales de vidrio de $10 \mathrm{ml}$, segmentos de hojas de $1 \mathrm{~cm}$ de lado en el Medio de cultivo Basal (MB), conteniendo macroelementos (Gamborg et al.,1968), microelementos (Murashige y Skoog, 1962), vitaminas (Morel, 1965 ) suplementado con $3 \mathrm{~g}$ de sacarosa, 0,3 g de fitagel y $0,01 \mathrm{mLde} 2,4 \mathrm{D}$ (2,4-diclorofenoxiacetico), a la mitad de su concentración, y a pH 5,8. Los cultivos se mantuvieron en incubación, con un fotoperíodo de 16 horas luz proporcionada por fluorescentes de 40 wats, a la temperatura de $25 \pm 1{ }^{\circ} \mathrm{C}, 8$ horas de oscuridad y humedad relativa de $85 \%$. A los 30 días se procedieron a cultivar las células a partir de los callos obtenidos.

\section{Cultivos Celulares}

En los cultivos celulares se utilizaron 2 medios líquidos: El Medio de Mantenimiento(MM; 
cuya base fue el MB y el Medio Inductor (MI) (Tabla 1), que fue suplementado con kinetina, ANA (Acido naftalenacético) y sacarosa a diferentes concentraciones: $0 \mathrm{mM}(\mathrm{T}), 58 \mathrm{mM}(\mathrm{A})$, $132 \mathrm{mM}(\mathrm{B})$ y $175 \mathrm{mM}(\mathrm{C})$.

En la cámara de siembra aséptica, se procedió a escoger callos de $1,5 \mathrm{~cm}$ de diámetro con coloración rojiza. Luego, se colocaron dos unidades de callo por matraz en $20 \mathrm{~mL}$ del MM. Los callos se desintegraron utilizando una bagueta estéril y se filtraron con un tamiz nylon, con la finalidad de obtener células libres. Posteriormente, el contenido se distribuyó en cuatro matraces, iniciándose con un volumen celular de $2 \times 10^{5}$ cel $/ \mathrm{mL}$ aproximadamente. Dichos matraces, de $125 \mathrm{~mL}$ de capacidad, se colocaron en un agitador orbital (100 rpm) con luz continua proporcionada por un fluorescente luz blanca de 40 wats, temperatura de $25 \pm 1{ }^{\circ} \mathrm{C}$, humedad relativa de $85 \%$ y durante siete días.

Luego de este periodo las células cultivadas en MM fueron transferidas a MI para ser sometidas a los tratamientos A, B y C (Tabla 1) comparados con un testigo el cual consistió en el MM sin sacarosa e identificado con la letra T. La siembra en MI se realizó en la cá- mara aséptica colocándose en matraces, $3 \mathrm{~mL}$ de células suspendidas en MM $\left(2 \times 10^{5} \mathrm{cel} /\right.$ $\mathrm{mL}$ aproximadamente), a cada uno de los tratamientos y al testigo. Cada matraz con 15 $\mathrm{mL}$ de MI, se colocaron en el agitador orbital (100 rpm), con luz blanca continua proporcionada por fluorescentes con intensidad lumínica de 5000 lux, temperatura de $25 \pm 1{ }^{\circ} \mathrm{C}$, humedad relativa de $85 \%$, durante 4 semanas. Se realizaron evaluaciones semanales para analizar su crecimiento, formas celulares, contenido y presencia de antocianinas a la vez que se renovaban los medios de cultivo. Cada ciclo se repitió 3 veces y las lecturas de los extractos se realizaron al final de cada ciclo.

\section{Evaluación del crecimiento celular}

Se utilizó una cámara de Neubauer American Optical adpatada para el conteo de células de vid, según la siguiente formula:

$$
\frac{\# \text { células contadas }}{m m^{3}}=\frac{\# \text { de células contadas } \times \text { factor }}{\text { Volumen }}
$$

Donde:

Factor $=5 \mathrm{y}$ Volumen $=0,4 \mathrm{~mm}^{3}$

Tabla 1. Medios inductores (MI) T, A, B y C en el cultivo de células de $V$. vinifera var. red globe.

\begin{tabular}{|c|c|c|c|c|}
\hline & \multicolumn{4}{|c|}{ Tratamientos } \\
\hline & $\mathbf{T}$ & A & B & $\mathrm{C}$ \\
\hline $\begin{array}{l}\text { Macroelementos (ml) } \\
\text { (Gamborg et al., 1968) } \\
\mathrm{KNO}_{3},\left(\mathrm{NH}_{4}\right)_{2} \mathrm{SO}_{4}, \mathrm{CaCl}_{2} 2 \mathrm{H}_{2} \mathrm{O}, \\
\mathrm{NaH}_{2} \mathrm{PO}_{4} 2 \mathrm{H}_{2} \mathrm{O}, \mathrm{MgSO}_{4} 7 \mathrm{H}_{2} \mathrm{O}\end{array}$ & 10 & 10 & 10 & 10 \\
\hline $\begin{array}{l}\text { Microelementos (ml) } \\
\text { (Murashige y Skoog, 1962) } \\
\mathrm{MnSO}_{4} \mathrm{H}_{2} \mathrm{O}, \mathrm{ZnSO}_{4} 7 \mathrm{H}_{2} \mathrm{O}, \mathrm{H}_{3} \mathrm{BO}_{3}, \\
\mathrm{KI}_{2} \mathrm{Na}_{2} \mathrm{MoO}_{4} 2 \mathrm{H}_{2} \mathrm{O}, \mathrm{CuSO}_{4} \mathrm{HH}_{2} \mathrm{O}, \\
\mathrm{CoCl}_{2} 6 \mathrm{H}_{2} \mathrm{O}, \mathrm{FeSO}_{4} 7 \mathrm{H}_{2} \mathrm{O}\end{array}$ & 0,1 & 0,1 & 0,1 & 0,1 \\
\hline $\begin{array}{l}\text { Vitaminas }(\mathbf{m l}) \\
\text { (Morel, 1965) } \\
\text { Mio-inositol, Acido nicotínico, Pantotenato } \\
\text { de calcio, Piridoxina, Tiamina }\end{array}$ & 0,1 & 0,1 & 0,1 & 0,1 \\
\hline Kinetina $(\mathrm{ml})$ & 0,04 & 0.04 & 0.04 & 0.04 \\
\hline ANA (ml) & 0,01 & 0.01 & 0.01 & 0.01 \\
\hline Sacarosa (g) & 0 & 1,985 & 4,5166 & 5,990 \\
\hline
\end{tabular}

El pH obtenido fue de 5,8. Volumen final $100 \mathrm{ml}$. 
Además se colorearon las células con azul de metileno para determinar su viabilidad.

\section{Cosecha de las células}

Después de 4 semanas las células en suspensión fueron separadas utilizando papel de filtro Watman $\mathrm{N}^{\mathrm{o}} 10$ y expuestas a la estufa por 24 horas.

\section{Extracción y lectura de antocianinas}

La extracción de antocianinas se realizó utilizando la marcha fitoquímica de Lock (1994) (Fig. 1) y la lectura de los extractos mediante un espectrófotometro UV Hewlett Packard a $535 \mathrm{~nm}$.

\section{Cuantificación de antocianinas}

La cantidad de antocianinas en los extractos se calculó de acuerdo a Vitrac et al. (2000). La curva patrón se construyó utilizando el coeficiente de extinción molar $(\log \varepsilon 4,53)$ y la ley de Beer (Willard et al., 1986).

\section{Análisis estadístico}

Los datos obtenidos de la cuantificación de antocianinas a las cuatro semanas se analizaron estadísticamente de acuerdo a un análisis de varianza (ANAVA) de un diseño completamente al azar, prueba de rango múltiple de Duncan y análisis de regresión polinómica con una probabilidad de error tipo I y con 0,05 de confiabilidad.

\section{Resultados}

El análisis de varianza (Tabla 2) muestra que existen diferencias significativas en la producción de antocianinas entre cada uno de los tratamientos a los que fueron sometidas las células de $V$. vinifera; y según la prueba de

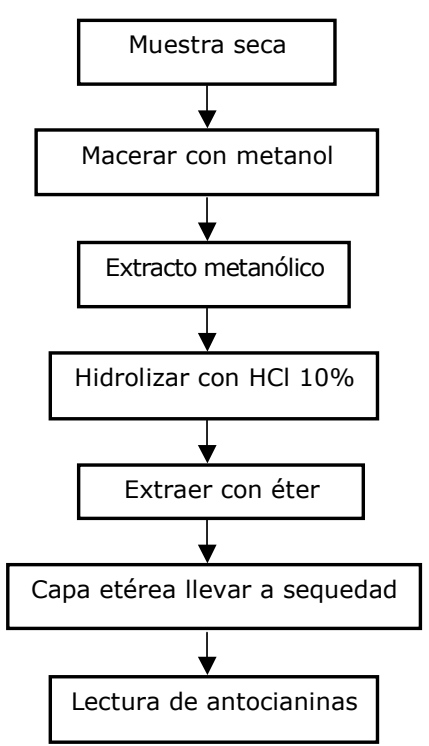

Figura 1. Marcha fitoquímica empleada en la extracción de antocianinas de los cultivos celulares de $V$. vinifera var. red globe «vid»

Tabla 3. Comparación en la producción de antocianinas por efecto de la concentración de sacarosa utilizando la prueba de Duncan con probabilidad de error tipo l y 0,05 de confiabilidad.

\begin{tabular}{lcccr}
\hline $\begin{array}{l}\text { Valor de } \\
\text { comparación }\end{array}$ & $\begin{array}{c}\text { Tratamientos } \\
(\mathrm{mM})\end{array}$ & $\begin{array}{c}\text { *Valores } \\
\text { Calculados }\end{array}$ & $\begin{array}{c}\text { Duncan } \\
\text { Tabulado }\end{array}$ \\
\hline \multirow{2}{*}{ (T) Testigo } & 175 & 0,807 & $>0,638$ \\
& 132 & 0,797 & $>0,623$ \\
& 58 & $0,588<$ & $<, 599$ \\
(A) 58 & 175 & $0,219<0,623$ \\
& 132 & $0,209<$ & $<, 599$ \\
(B) 132 & 175 & 0,01 & $<0,599$ \\
(C) 175 & 0 & - & & - \\
\hline
\end{tabular}

* Valor calculado $>$ valor tabulado: Diferencia significativa

Tabla 2. Análisis de varianza de un diseño completamente al azar para la producción de antocianinas en cultivos celulares de $V$. vinifera «vid» var. red globe con probabilidad de error tipo I y 0,05 de confiabilidad.

\begin{tabular}{lccccc}
\hline Fuente de Variación & $\begin{array}{c}\text { Grados de } \\
\text { Libertad }\end{array}$ & $\begin{array}{c}\text { Suma de } \\
\text { Cuadrados }\end{array}$ & $\begin{array}{c}\text { Cuadrado } \\
\text { Medio }\end{array}$ & F c & F t \\
\hline Media & 1 & 35,017 & & & \\
Tratamientos & 3 & 1,293 & 0,431 & $4,244 *$ & 4,066 \\
Error Experimental & 8 & 0,812 & 0,102 & & \\
Total & 12 & 37,123 & & & \\
\hline
\end{tabular}

$* \mathrm{Fc}>\mathrm{Ft}$ : diferencia significativa 
Duncan (Tabla 3) existen diferencias significativas entre los tratamientos $\mathrm{B}$ y $\mathrm{C}$ con respecto al testigo, siendo la producción de antocianinas halladas a $132 \mathrm{mM}$ (B) y $175 \mathrm{mM}$ (C) de sacarosa significativamente mayores que el testigo. Asimismo, la producción de antocianinas van aumentando conforme se incrementa la concentración de sacarosa (Tabla 4), siendo la máxima producción de 1,97 $\mu \mathrm{M}$ a $175 \mathrm{mM}$ de sacarosa (tratamiento $\mathrm{C}$ ).

El análisis de regresión (Fig. 2) identifica el punto de mayor producción de antocianinas el obtenido con el tratamiento B, a $132 \mathrm{mM}$ de sacarosa. El crecimiento y viabilidad celular se monitorearon semanalmente en vista de los diferentes tratamientos sometidos, desarrollándose un patrón relativamente estable en las cuatro semanas en A con $329,1 \mathrm{cel} . \mathrm{mm}^{3}$, B con $312,5 \mathrm{cel} . / \mathrm{mm}^{3}$ y $\mathrm{C}$ con 216,6 , cel. $/ \mathrm{mm}^{3}$, y un aumento continuo de crecimiento celular en $\mathrm{T}$, alcanzando 758, 7 cel. $/ \mathrm{mm}^{3}$ (Tabla 5).

\section{Discusión}

En este trabajo se ha determinado que la producción de antocianinas aumenta a $1,97 \mu \mathrm{M}$ a medida que se incrementa la concentración de sacarosa hasta $175 \mathrm{mM}$ (Tabla 4), lo que indica que las células aumentan su capacidad de sintetizar antocianinas a concentraciones crecientes de sacarosa. Cabe señalar que Cormier et al. (1989); Decendit (1996) y Kim y Kim (2002a) reportan resultados coincidentes a los encontrados en el presente trabajo. Sin embargo, cuando la concentración de sacarosa al-

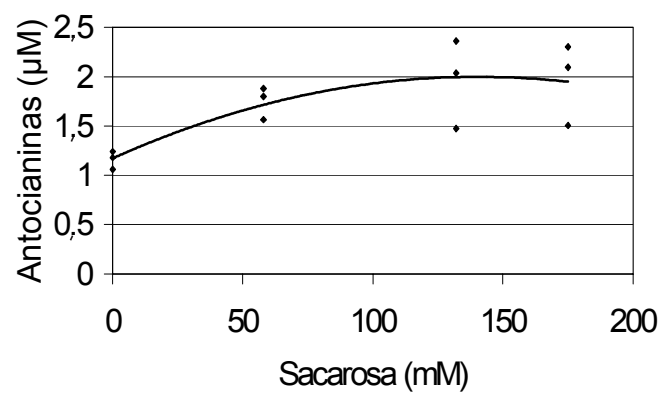

Figura 2. Curva de regresión entre la concentración de sacarosa y la producción de antocianinas donde se observa que el punto más alto es $132 \mathrm{mM}$ de sacarosa.
Tabla 4. Concentraciones de sacarosa y producción de antocianinas en células de $V$. vinifera var. red globe «vid»

\begin{tabular}{lc}
\hline $\begin{array}{l}\text { Tratamientos } \\
(\text { Sacarosa } \mathbf{m M})\end{array}$ & $\begin{array}{c}\text { Produccion de } \\
\text { Antocianinas }(\boldsymbol{\mu M})\end{array}$ \\
\hline $\mathrm{T}(0)$ & 1,16 \\
$\mathrm{~A}(58)$ & 1,75 \\
$\mathrm{~B}(132)$ & 1,96 \\
$\mathrm{C}(175)$ & 1,97 \\
\hline
\end{tabular}

canzó $58 \mathrm{mM}$ estimuló una menor producción de antocianinas en $1,75 \mu \mathrm{M}$ y ninguna producción en el grupo testigo con $0 \mathrm{mM}$ de sacarosa. Decendit y Mérillon (1996) y Kim y Kim (2002b) llegaron a similares conclusiones en cultivos celulares de Vitis sp.

En general concentraciones crecientes de sacarosa favorecen la producción de antocianinas (Cormier et al., 1989; Do y Cormier, 1991; y Kim y Kim, 2002a) sin embargo la declinación de la curva observada en la figura 5 se debería a que elevados niveles de sacarosa crean condiciones de estrés osmótico lo cual inhibe el crecimiento celular, pero a su vez, mejora la acumulación de antocianinas (Cormier et al., 1989; Do y Cormier, 1991). Asímismo, Kim y Kim (2002b), explican que el estrés osmótico o alta viscosidad del medio, inhibe la captación del nutriente bloqueando las rutas metabólicas responsables de la síntesis de antocianinas y activándose otras.

En cada especie de Vitis, la concentración de sacarosa debe variar para obtener una máxima producción de antocianinas. Kim y Kim (2002a), encontraron que la concentra-

Tabla 5. Incremento celular semanal (número de celulas $/ \mathrm{mm}^{3}$ ) en cultivos de $V$. vinifera var. red globe «vid» por cada tratamiento: $\mathrm{T}(0 \mathrm{mM})$, A (58 mM), B (132 mM), C (175 mM).

\begin{tabular}{ccccc}
\hline Tiempo & \multicolumn{4}{c}{ Tratamientos } \\
& $\mathrm{T}$ & $\mathrm{A}$ & $\mathrm{B}$ & $\mathrm{C}$ \\
\hline Semana 1 & 153,3 & 216,6 & 204,1 & 262,5 \\
Semana 2 & 191,6 & 216,6 & 229,1 & 337,5 \\
Semana 3 & 391,6 & 362,5 & 516,6 & 312,5 \\
Semana 4 & 758,7 & 329,1 & 312,5 & 216,6 \\
\hline
\end{tabular}


ción de sacarosa con una apropiada producción de antocianinas fue a $204 \mathrm{mM}$ y la concentración más conveniente para el incremento de las antocianinas totales fue $146 \mathrm{mM}$ en Vitis vinifera var. sheridan; sin embargo, en el presente trabajo, la producción máxima de antocianinas se obtuvo a una concentración de $175 \mathrm{mM}$ de sacarosa (Tratamiento C) y el punto óptimo de sacarosa para la producción de antocianinas fue $132 \mathrm{mM}$ (Tratamiento B), esta diferencia en los resultados puede atribuirse a la variedad red globe de Vitis vinifera utilizada en el presente trabajo.

\section{Literatura citada}

Bailly, C.; F. Cormier, y C. Do. 1996. Characterization and activities of S-adenosyl-1-methionine: cyanidin 3glucoside 3'-O-methyltransferase in relation to anthocyanin accumulation in Vitis vinifera cell suspension cultures. Plant Science 122(1): 81-89.

Bruneton, J. 1991. Elementos de Fitoquímica y Farmacognosia. Edit. Acribia S.A. Zaragoza. España.

Callebaut, A.; A. Voets and J. Motte. 1990. Anthocyanin production by plant cell cultures on media based on milk whey. Biotechnology Letters 12: 215-218.

Cormier, F.; H. Crevier and Ch. Do. 1989. Effects of sucrose concentration on the accumulation of anthocyanins in grape (Vitis vinifera) cell suspension. Journal of Botanic 98: 1822-1825.

Decendit, A. and J. Mérillon. 1996. Condensed tannin and anthocyanin production in Vitis vinifera cell suspension cultures. Plant cell reports 15:762-765.

Do, Ch. and F. Cormier. 1991. Effects of low nitrate and high sugar concentrations on anthocyanins content and composition of grape (Vitis vinifera L.) cell suspension. Plant Cell Reports 9: 500-504.

Endress, R. 1994. Plant cell biotechnologies. $2^{\circ} \mathrm{Ed}$. Springer Verlg. Washington D. C.

Evans, W. 1998. Farmacognosea. $13^{\circ}$ Edic. Edit. Nueva editorial Interamericana Mc. Graw Hill S.A. de C.V. México.

Gamborg, O.; R. Miller \& K. Ojima. 1968. Nutrient requirements of suspension cultures of soybean root cells. Experimental Cell Research. 50: 151.

Hurtado M, y M. Merino. 1994. Cultivo de Tejidos Vegetales. $3^{\circ}$ Ed Trillas. México D. F. México.

Kim, Seung-Heui \& S. K, Kim. 2002. Effects of sucrose level and nitrogen sourve on fresh weigh and anthocyanin production in cell suspension culture of «Sheridan» grape (Vitis spp.). Journal of Plant Biotechnology 4(1):23-27
Kim, Seung-Heui. \& S. K, Kim. 2002. Effects of 2,4-D, $\mathrm{BA}$, and sucrose on growth, production of anthocyanin, $\mathrm{pH}$, and sugar content in «sheridan» grape cell suspension cultures. Journal of Plant Biotechnology 4(2): 77-82.

Lindsey, K. y M. Jones. 1992. Biotecnología Vegetal Agrícola. Ed. Acribia S.A. Zaragoza. España.

Lock, O. 1997. Colorantes Naturales. Edit. Fondo Editorial de la Pontificia Universidad Católica del Perú. Lima. Perú.

Morel, G.1965. Clonal propagation of orchids by meristems culture. Cymbidium Soc News 20: 3.

Mori, T. and M. Sakurai. 1994. Production of anthocyanin from strawberry cell suspension cultures; effects of sugar and nitrogen. Journal of Food Science 59(3): 588-593.

Murashige, T. and F. Skoog. 1962. A revised medium for rapid growth and bioassays with tobacco tissue cultures. Physiology Plant 15: 473.

Pierik, R. 1990. Cultivo In Vitro de las Plantas Superiores. $3^{\circ}$ Edic. Edit. Ediciones Mundi-Prensa. Madrid. España.

Piñol, M. 1999. Aplicación de las Nuevas Tecnologías para la Producción de Metabolitos Secundarios. XIII Reunion Nacional de la Sociedad Española de Fisiologia Vegetal. VI Congreso Hispano Uso de la Fisiologia Vegetal. Sevilla. España.

Sato, K.; M. Nakayama and J. Shigueta. 1998. Culturing conditions affecting the production of anthocyanin in suspended cell cultures of strawberry. Plant Science 113(1): 91-98.

Serrano, M. Y M. Piñol. 1991. Biotecnología Vegetal. Ed. Síntesis. Madrid. España.

Vitrac, X.; F. Larronde; S. Krisa; A. Decendit; G. Deffieux; J.M. Mérillon. 2000. Sugar sensing and Ca $2+$-calmodulin requeriment in Vitis vinifera cells producing anthocyanins. Phytochemistry 53: 659-665.

Willard, H.; L. Merrit; J. Dean y F. Settle. 1986. Métodos instrumentales y de análisis. Compañía editorial Continental S.A. de C. V. México.

Xu, W.; K. Moriya; K. Yamada; M. Kondo; M. Nishimura; H. Shioiri; M. Kojima and M. Nozue. 2000. Detection and characterization of a $36-\mathrm{Kda}$ Peptide dereived from a $24-\mathrm{kDa}$ vacuolar protein (VP24) precursor in anthocyanin-producing sweet potato cells in suspension culture.

Xu, W.; H. Shioiri, M. Kojima and M. Nozue. 2001. Primary structure and expression of a 24-KD vacuolar protein (VP24) precursor in anthocyanin-producing cells of sweet potato in suspension culture. Plant Physiology 125:447-455.

Zhang, W.; M. Seki and S. Furusaki. 1998. Effect of temperature and its shift on growth and anthocyanin production in suspension cultures of strawberry cells. Plant Science 127(2) pp. 207-214. 